\title{
Differences in the courses of meningococcal and pneumococcal cerebrospinal meningitis
}

\author{
Wojciech Szymański ${ }^{1,3}$, Krzysztof Simon ${ }^{1,3}$, Marta Rorat ${ }^{2,3}$ \\ ${ }^{1}$ Department of Infectious Diseases and Hepatology, Wroclaw Medical University, Poland \\ ${ }^{2}$ Department of Medical Law, Department of Forensic Medicine, Wroclaw Medical University, Poland \\ ${ }^{3} 1$ st Department of Infectious Diseases, J. Gromkowski Regional Specialistic Hospital in Wroclaw, Poland
}

\begin{abstract}
Neisseria meningitidis and Streptococcus pneumoniae are the most common pathogens causing cerebrospinal meningitis (CSM) in adults. The mortality rate and the number of complications remain high. In our study, retrospective evaluations were conducted on data concerning 98 adult patients with bacterial cerebrospinal meningitis caused by Neisseria meningitidis $(n=42)$ and Streptococcus pneumoniae $(n=56)$, hospitalised at the Regional Specialistic Hospital in Wroclaw (Poland) within the period 1998-2018.

Compared to the group infected with S. pneumoniae, patients infected with $N$. meningitidis were younger and were less often affected by an additional disease burden; they presented more frequently with haemorrhagic rashes. Compared to the S. pneumoniae group, in patients with meningococcal CSM, cytosis in cerebrospinal fluid measuring $<1,000$ cells $/ \mathrm{mL}$ was less frequent; intravascular coagulation syndrome appeared more frequently; the hospitalisation time was shorter and the rate of mortality was lower. Meningococcal meningitis occurs more frequently among young people with no history of disease. It is characterised by the rapid development of symptoms, which results in earlier diagnosis and more favourable prognosis compared to cases of $S$. pneumoniae. Irrespective of the pathogen, advanced age and a level of cytosis in cerebrospinal fluid of $<1,000$ cells $/ \mu \mathrm{l}$ indicate an unfavourable prognosis.
\end{abstract}

Key words: neuroinfection, pneumococcal meningitis, meningococcal meningitis

(Neurol Neurochir Pol 2020; 54 (1): 39-46)

\section{Introduction}

Bacterial cerebrospinal meningitis is an acute life-threatening infection of the central nervous system (CNS) which poses serious diagnostic and therapeutic problems. These infections require urgent diagnostics and therapy, interdisciplinary and multidirectional medical care, often including hospitalisation in critical care units and long-term treatment of complications.

In Poland, about 3,000 cases of meningitis (of all aetiologies) are recorded every year, of which about one-third are infections of bacterial aetiology; thus, the incidence of this disease is estimated at approximately $2-2.5 / 100,000$ inhabitants [1]. Children up to four years of age are particularly susceptible to infection (incidence of $7 / 100,000$ ) [2]. The incidence of bacterial CNS infections may be underestimated, despite mandatory reporting of infections. According to reports from Regional Sanitary-Epidemiological Stations 121 cases of cerebrospinal meningitis (CSM) of N. meningitidis aetiology occurred in Poland in 2015, whereas the National Reference Centre for the Diagnosis of Bacterial Infections of the Central Nervous System reported 200 cases of invasive meningococcal disease $[3,4]$.

Of bacterial CSM cases, $35-45 \%$ were caused by encapsulated bacteria - Neisseria meningitidis, Streptococcus pneumoniae and Haemophilus influenzae - with the share of the last-named being marginal, constituting $<5 \%$ of cases $[1,2]$. Despite widespread and easy access to anti-microbial

Address for correspondence: Wojciech Szymański, Department of Infectious Diseases and Hepatology, Wrocław Medical University, Koszarowa 5 Str., 51-141 Wroclaw, Poland, e-mai: szymanski.wojciech9@gmail.com 
treatment, the rate of mortality due to bacterial CSM in Poland remains at $20-30 \%$, reaching $50 \%$ in patients over 65 years of age $[5,6]$. This is associated not only with the virulence of the pathogens, but frequently with delayed treatment.

Despite the effectiveness of antibiotic therapy, many patients develop serious complications, including tissue necrosis, amputation of limbs, organ damage and permanent neurological consequences such as intellectual disabilities, personality changes, hearing loss, paresis, etc. $[7,8]$. The adverse consequences of infections significantly reduce patients' quality of life and may be responsible for re-hospitalisation.

There are some studies from Sweden, Finland and from the Netherlands suggesting that $S$. pneumoniae infection is associated with higher mortality and higher rates of unfavourable outcome, also affecting older patients with disease burden [9-13]. On the other hand, researchers from Portugal have linked $N$. meningitidis with a higher probability of neurological sequelae than S. pneumoniae [14].

The clinical course, especially mortality, of infectious diseases may be geographically diverse, which is the result of the local spread of serotypes, differences in hosts' susceptibility (i.e. genetic factors), but also differences in the organisation of healthcare systems. Especially this last element influences mortality and sequelae rates as it affects the timing of medical assistance, diagnosis and the prompt implementation of proper treatment [15].

\section{Clinical rationale for the study}

Our work is the first Polish study to investigate differences between clinical courses of these two aetiologies. Also the period of time (20 years) is significant. It is worth underlining that only confirmed cases of meningitis of these two aetiologies were analysed, and therefore the results of this study should be reliable.

Other researchers from Poland have focused on epidemiological studies (i.e. the occurrence of meningitis in different age groups, bacterial serotypes isolated from cerebrospinal fluid and their susceptibility to antibiotics, etc.) or analysis distinguishing between suppurative and aseptic meningitis, and have not noticed changes in the clinical course related to these two aetiologies [16-18].

\section{Materials and methods}

Data from adult patients ( $\geq 18$ years old) hospitalised in the period 1998-2018 at the J. Gromkowski Regional Specialistic Hospital in Wroclaw (Poland) with confirmed cerebrospinal meningitis (defined as changes in cerebrospinal fluid with general symptoms) of known aetiology (i.e. N. meningitidis or S. pneumoniae) were analysed.

The following were subjected to evaluation: demographic factors (age, gender), the month in which the disease occurred, department of hospitalisation (Infectious Diseases and/or
Anaesthesiology and Intensive Care), duration of symptoms up to the moment of hospital admission, presence of disease burden and other risk factors reported in literature, reported complaints and clinical symptoms found in patients, results of cerebrospinal fluid examinations, blood test results, organ failure, presence of pneumonia at any time during hospitalisation (defined as a new chest X-ray finding with general symptoms), duration of hospitalisation, presence of complications, and mortality.

The following were used in the analysis: for qualitative data - Fisher's exact test; for quantitative data - the Mann-Whitney test. Analysis of the relationship between cytosis $<1,000$ cells $/ \mu \mathrm{l}$ and complications as well as mortality was performed using Fisher's exact test.

Multiple factor analysis of the impact of the studied groups, age and cytosis on mortality and complications was carried out by means of multiple logistic regression. The entire analysis was carried out using the statistical package $\mathrm{R}$ for Windows (version 3.5) [19].

\section{Results}

Among adult patients hospitalised at the J. Gromkowski Regional Specialistic Hospital because of bacterial CSM, 42 cases (28 men, 67\%) of N. meningitidis aetiology and 56 cases (36 men, 64\%) of S. pneumoniae aetiology were identified.

Patients infected with $N$. meningitidis ranged from 19-74 years (average $34 \pm 16$ ), including $30(71 \%)$ patients aged $<40$ years; five $(12 \%)$ patients had been diagnosed with chronic diseases, e.g. hypertension, type 2 diabetes, alcoholism, sideropenic anaemia, paroxysmal atrial fibrillation, grade 3 obesity, fatty liver disease and polyneuropathy; 11 (26\%) patients were characterised by at least one risk factor for CSM (Tab. 2).

The time elapsed from the onset of the first symptoms to admission to hospital is summarised in Table 1.

The general condition of 29 (69\%) patients upon admission was defined as serious. Assessments of general condition were carried out by a clinician on the basis of state of consciousness, physical symptoms, and a physical examination. The classic 'triad' of symptoms in the form of neck stiffness, fever, and disturbances of consciousness occurred in seven (17\%) patients.

No evidence of seasonal incidence was observed.

The results of laboratory tests are listed in Table 1. In the examination of cerebrospinal fluid collected at admission, segmental cells were dominant in the smear in each case. In the morphology of peripheral blood, thrombocytopaenia, which appeared in $20(48 \%)$ cases, drew attention. Concentration of C-reactive protein (CRP) showed a significant range of values, from 2 to $443 \mathrm{mg} / \mathrm{L}$ (average 204). Procalcitonin concentration was determined in only eight patients (due to the unavailability of the test until 2010); the results were in the range of $7.02-78 \mathrm{ng} / \mathrm{mL}$ (average 24.96). 


\begin{tabular}{|c|c|c|c|}
\hline & $\begin{array}{l}\text { N. meningitidis } \\
(n=42)\end{array}$ & $\begin{array}{l}\text { S. pneumoniae } \\
(n=56)\end{array}$ & $\begin{array}{l}\text { Statistical } \\
\text { difference }\end{array}$ \\
\hline Age (avg. \pm SD) & $34 \pm 16$ years & $51 \pm 16$ years & $p=2.1 \times 10-6$ \\
\hline Presence of chronic diseases (n) & $5(12 \%)$ & $43(77 \%)$ & $p=2.1 \times 10-5$ \\
\hline \multicolumn{4}{|c|}{ Time elapsed to admission to hospital (n): } \\
\hline - $<24 \mathrm{~h}$ & - $23(50 \%)$ & - $17(30 \%)$ & - none \\
\hline - $24-72 \mathrm{~h}$ & - $10(24 \%)$ & - $10(18 \%)$ & - none \\
\hline - $>72 \mathrm{~h}$ & - $0(0 \%)$ & - $17(30 \%)$ & - $p=8.3 \times 10-5$ \\
\hline - No data & - $11(26 \%)$ & - $12(21 \%)$ & - $\mathrm{n} / \mathrm{d}$ \\
\hline \multicolumn{4}{|l|}{ Accompanying symptoms (n): } \\
\hline - neck stiffness & - $37(88 \%)$ & - $47(84 \%)$ & - none \\
\hline - other meningitis symptoms & - $24(57 \%)$ & - $33(59 \%)$ & - none \\
\hline - consciousness disturbances & - $24(57 \%)$ & • $41(73 \%)$ & - none \\
\hline - fever & - $20(48 \%)$ & - $49(89 \%)$ & - $p=3.5 \times 10-5$ \\
\hline - headache & - $31(74 \%)$ & - $28(50 \%)$ & - $p=0.022$ \\
\hline - vomiting & - $33(79 \%)$ & - $12(21 \%)$ & - $p=9 \times 10-9$ \\
\hline - haemorrhagic rash & . $26(62 \%)$ & - $2(4 \%)$ & - $p=10-10$ \\
\hline \multicolumn{4}{|l|}{ PMR results (avg./range): } \\
\hline 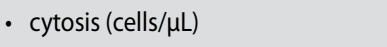 & . $6,846 / 10-25,000$ & - $4,293 / 10-40,000$ & $p=0.018$ \\
\hline - cytosis < 1,000 cells/ $\mu \mathrm{L}(\mathrm{n})$ & - $7(24 \%)$ & • $22(39 \%)$ & $p=0.013$ \\
\hline - $\operatorname{protein}(\mathrm{mg} / \mathrm{dL})$ & . $472 / 30-926$ & - $597 / 45-6,000$ & - none \\
\hline - glucose (mg/dL) & . $16 / 0-72$ & . $11 / 0-54$ & - none \\
\hline - chlorides (mmol/L) & . 117/106-134 & - $114 / 89-135$ & - none \\
\hline \multicolumn{4}{|l|}{ Peripheral blood count (n): } \\
\hline - Anaemia & - $7(17 \%)$ & - $24(43 \%)$ & - $p=0.004$ \\
\hline - Leucocytosis & - $34(81 \%)$ & - $48(86 \%)$ & - none \\
\hline - Leucopaenia & - $1(2 \%)$ & - $2(4 \%)$ & - none \\
\hline - Thrombocytopaenia & - $20(48 \%)$ & - $16(29 \%)$ & - none \\
\hline $\operatorname{DIC}(n)$ & $13(31 \%)$ & $1(2 \%)$ & $p=4.5 \times 10-5$ \\
\hline Pneumonia (n) & $4(10 \%)$ & $16(29 \%)$ & $p=0.024$ \\
\hline Time of hospitalisation (avg./range) & 18/9-55 days & 27/4-122 days & $p=0.036$ \\
\hline Mortality (n) & $0(0 \%)$ & $12(21 \%)$ & $p=0.001$ \\
\hline
\end{tabular}

Seven patients (17\%) were diagnosed with septic shock, respiratory failure occurred in one-third of patients, and acute kidney injury (AKI) in $10(24 \%)$ patients. Hepatic failure was found in one patient (2\%). Ten (24\%) patients required hospitalisation in the Department of Anaesthesiology and Intensive Care. In 11 (26\%) patients additional organ complications appeared in the form of hydrocephalus, cerebral oedema, hemiparesis, upper limb paresis, neuropathy of the median nerve, endophtalmitis, eyeball haemorrhage, cardiac arrhythmia and reactive arthritis.

Adjunctive corticosteroid therapy was administered to all patients.
Patients infected with $S$. pneumoniae ranged from 22 to 81 years (average $51 \pm 16$ ), of whom $14(25 \%)$ were $<40$ years. In 43 patients (77\%) chronic diseases were present, including: hypertension, coronary heart disease, cardiac arrhythmias, bronchial asthma, chronic bronchitis, peptic ulcer disease, chronic gastritis and oesophagitis, toxic liver damage, fatty liver disease, chronic hepatitis B or $\mathrm{C}$, liver cirrhosis, chronic pancreatitis, type 2 diabetes, alcoholism, drug addiction, epilepsy, post-inflammatory encephalopathy, hypothyroidism, systemic lupus erythematosus, HIV infection, and plasma cell myeloma. At least one risk factor of infection was present in 39 (70\%) patients (Tab. 2). 
Table 2. Distribution of risk factors of CSM in study population $[6,7,8]$

\begin{tabular}{|c|c|c|}
\hline Risk factors & $\begin{array}{l}\text { N. meningitidis } \\
(n=42)\end{array}$ & $\begin{array}{c}\text { S. pneumoniae } \\
(n=56)\end{array}$ \\
\hline Crowding, including: & 4 & N/A \\
\hline - prison term & 1 & \\
\hline - stay in a boarding school & 1 & \\
\hline $\begin{array}{l}\text { - work in a pre-school } \\
\text { or greenhouse }\end{array}$ & 2 & \\
\hline Low socio-economic status & $\mathrm{n} / \mathrm{a}$ & 3 \\
\hline Previous history of CSM & 4 & 7 \\
\hline Splenectomy & 0 & 2 \\
\hline Liver cirrhosis & 1 & 2 \\
\hline Sinusitis & 1 & 11 \\
\hline Alcoholism & 2 & 10 \\
\hline Diabetes & 1 & 6 \\
\hline Emaciation & $\mathrm{n} / \mathrm{a}$ & 2 \\
\hline Cancer & $\mathrm{n} / \mathrm{a}$ & $\begin{array}{l}1 \text { (plasma cell } \\
\text { myeloma) }\end{array}$ \\
\hline
\end{tabular}

Time elapsed until admission to the hospital is presented in Table 1.

In 46 (82\%) patients, the general condition upon admission was defined as serious. Assessments of general condition were carried out in the same way as in the group infected with $N$. meningitidis. The classic triad of symptoms occurred in 33 (59\%) patients.

No evidence of seasonal incidence was observed.

Demographic, clinical and laboratory data on these patients is also presented in Table 1. In the cerebrospinal fluid, in each case, the smear was dominated by segmental cells. In the morphology of peripheral blood, anaemia, which appeared in 24 (43\%) cases, drew attention. CRP concentration averaged $197 \mathrm{mg} / \mathrm{L}$ and fluctuated within the range of $16-500 \mathrm{mg} / \mathrm{L}$. Procalcitonin was performed in 16 patients; the average concentration was $17.6 \mathrm{ng} / \mathrm{mL}$ (range 0.3-100).

Septic shock occurred in $15(27 \%)$ patients, circulatory failure in $17(30 \%)$, respiratory failure in $27(48 \%)$, acute kidney injury in 21 (38\%), and hepatic failure in two (4\%). A total of $33(59 \%)$ patients required hospitalisation in critical-care conditions.

$23(43 \%)$ patients developed complications, including: ischaemic stroke, haemorrhagic stroke, hydrocephalus, limb paresis, epilepsy, polyneuropathy, cranial nerve palsy, post-inflammatory encephalopathy, hearing loss, infective endocarditis, and gastrointestinal bleeding.

Adjunctive corticosteroid therapy was administered to 53 patients $(95 \%)$.

\section{Statistical analysis}

The differences, including assessments of statistical significance, between groups in terms of demographic factors, occurrence of associated symptoms, length of hospitalisation and mortality are presented in Table 1.

No significant differences were noted in the frequency of complications and ICU (intensive care unit) hospitalisation between the two groups of patients.

Regardless of the aetiological factor, cytosis $<1,000$ cells/ $\mu \mathrm{l}$ was correlated with a higher rate of mortality $(\mathrm{p}=0.0058)$ and more frequent ICU hospitalisation $(\mathrm{p}=0.0039)$, while age $>60$ years was a factor increasing the risk of death $(\mathrm{p}=0.02)$.

In the process of multiple factor analysis, it was shown that along with increasing age, irrespective of CSM aetiological factor, the need for ICU hospitalisation and risk of death increased; the risk of organ-related complications also increased.

Similarly, regardless of the group, it was found that cytosis $<1,000 \mathrm{cells} / \mu \mathrm{l}$ in cerebrospinal fluid was associated with a greater risk of severe disease course, as well as greater risks of hospitalisation in ICU and of death.

\section{Discussion}

In a series of clinical observations it has been demonstrated that many factors influence the course of meningitis, including: age, sex, the patient's disease burden and general condition (including state of consciousness) upon admission to hospital, mean arterial pressure, leucocyte and platelet counts, cerebrospinal fluid cytosis, and aetiological factors [7, 20, 21].

In the analysed material, CSM caused by $N$. meningitidis occurred more frequently in the group of younger patients than did CSM caused by S. pneumoniae. This is in agreement with epidemiological data on invasive meningococcal disease in Poland and throughout the world, according to which the frequency of its occurrence decreases with age, whereas the incidence of invasive pneumococcal disease is highest in the groups $<4$ and $>65$ years of age $[3,22,23]$. This age distribution may be due to pathogen exposure: asymptomatic carriage of $N$. meningitidis initially increases with age, peaking (at 24-37\%) in the group of 15 to 24 -year-olds, and subsequently falling to less than $10 \%$ at more advanced ages [24]. Another risk factor for invasive meningococcal disease is crowding in places such as barracks, prisons, and boarding schools [25], which most typically house young populations. Considering the percentage of carriers in this age group, crowding additionally increases their exposure to the pathogen.

Irrespective of bacteria, a higher rate of mortality and a greater risk of death in patients $>60$ years have been demonstrated in both groups, which accords with other reports [26]. This may be an expression of a progressive qualitative and quantitative deterioration of the immune system with age [27].

The population with pneumococcal CSM was characterised by a greater disease burden in terms of internal disease and that risk factors for meningitis were more likely to be present, as a result of the fact that the incidence of chronic diseases and medical interventions increases along with age, which is consistent with global epidemiological data [28]. 
The time elapsed from the onset of the first symptoms to hospital admission also varied. Patients with pneumococcal disease were hospitalised more frequently after 72 hours since the appearance of the first symptoms compared to the group with meningococcal infections (Tab. 1). In 18 cases (32\%), pneumococcal CSM was preceded by a localised infection (otitis, sinusitis, pneumonia) with a milder course. CSM was most likely a complication of the primary infection. This may explain the delay in seeking help and the longer time to develop symptoms. In our study, patients with meningococcal infections were admitted after a shorter period of time elapsed from the onset of symptoms than those with pneumococcal infections. N. meningitidis infection was definitely characterised by a more dynamic course than S. pneumoniae. In accordance with the data from the literature, the median time elapsed from the onset of symptoms to hospital admission for invasive meningococcal disease is in the range of $12-24 \mathrm{~h}$, depending on the course of the disease [24], as well as on the patient's age: for the group of 15- to 16-year-olds, the median was $22 \mathrm{~h}$, for children < 1 year of age, it was $13 \mathrm{~h} \mathrm{[29].}$

There was no significant difference in general condition upon admission between the groups; however, it should be remembered that this is a subjective and imprecise criterion. More sudden development of the disease, which is undoubtedly associated with a more urgent need for hospitalisation, may hasten the implementation of empirical antibiotic therapy in the N. meningitidis group, early inclusion of which is of key significance for the prognosis [15].

Headache and vomiting were significantly more common in the N. meningitidis group, and fever in the S. pneumoniae group. The classic triad of symptoms - neck stiffness, fever and disturbed consciousness - rarely occurred in the group with meningococcal infection in contrast to the pneumococcal CSM group, which is consistent with the observations of other clinicians. The literature indicates an approximate sensitivity rate of $60 \%$ for this constellation of symptoms in disease diagnosis [30, 31].

In our material, haemorrhagic rashes were found in $62 \%$ of patients with meningococcal infection, which falls within the $28-78 \%$ range described by other authors, and in only $4 \%$ of patients with CSM in the course of S. pneumoniae infection [20, 32]. The more frequent presence of haemorrhagic rashes in the $N$. meningitidis group is not a surprising phenomenon, as it is part of the picture of the disease described in the literature; the bacterium itself is one of the most common infectious agents causing such changes [22, 30,33]. However, haemorrhagic rash is not pathognomonic for invasive meningococcal disease; it also occurs, although less frequently, in the course of invasive infections due to S. pneumoniae, S. aureus, $H$. influenzae and other pathogens [34].

In both groups, the result of cerebrospinal fluid analysis was similar and typical of bacterial CSM [7]. One statistically significant difference was the pleocytosis: the total number was lower in the pneumococcal group. According to the data in the literature, relatively low cytosis $(<1,000$ cells $/ \mu \mathrm{l})$ is associated with an unfavourable course of the disease [35].

In our study, we showed that cytosis of $<1,000 \mathrm{cells} / \mu \mathrm{l}$ is associated (regardless of the pathogen) with a significantly higher mortality rate and more frequent hospitalisation in intensive care units. According to Weisfelt et al., low pleocytosis is associated with an inadequate or moderate immune response, and is described as a factor associated with a poor prognosis [26], which we observed as well in our material. Low pleocytosis also appears in the early stages of infections, especially meningococcal ones [36].

It appears that the greater incidence of anaemia in the pneumococcal group compared to that infected with $N$. meningitidis may be associated with the greater incidence of other systemic diseases in this group and is more likely a manifestation of these diseases, the more so given that a higher percentage of patients with DIC or haemolysis was not observed in this group. On the contrary, intravascular coagulation syndrome occurred significantly less frequently than in the meningococcal group. There is no precise data in the literature on the incidence of anaemia in bacterial CSM. In both groups, leucocytosis was found in the vast majority of patients. Our analysis showed no differences between groups in terms of the incidence of leucocytosis and leucopaenia. Total values were not analysed.

In the group of patients with pneumococcal infections, pneumonia was found with significantly greater frequency compared to the meningococcal group. This can be explained by three mechanisms: the presence of pneumonia upon admission as the primary source of the infection; blood-borne pneumonia as a result of the dissemination of pathogens; and secondary pneumonia associated with hospitalisation (prolonged stay in a supine position, colonisation by hospital pathogens, poor ventilation due to serious overall condition, respiratory therapy, etc.).

Another factor conducive to the occurrence of pneumonia is duration of hospitalisation [37], which is significantly greater in the pneumococcal group. This is the result of all of the features of the group in question: the age of the patients, risk factors, comorbidities, and the pathogen itself, which constitutes an independent unfavourable prognostic factor.

In accordance with the relevant definition, the diagnosis of DIC cases in our study was made by a clinician on the basis of symptoms of bleeding diathesis and (often multiple) laboratory assays of coagulation system parameters, which, however, were not always supported by the point scale [38]. N. meningitidis possesses significant potential for the development of DIC, due, among other factors, to the presence of lipopolysaccharide (LPS), which is absent in S. pneumoniae; this may explain differences between the groups [38-41].

In both meningococcal and pneumococcal CSM, neurological complications develop in $12-41 \%$ of patients (depending on the pathogen), among which the most common is hearing impairment, affecting $24 \%$ of patients with pneumococcal 
infections and $8 \%$ with meningococcal infections [42-44]. Neurological complications also predominated in our observations. However, given the retrospective nature of our study and the lack of thorough neurological or audiometric evaluation upon discharge from hospital or during convalescence, we cannot precisely compare our data to the observations of other authors.

In our study we did not find statistical differences between groups in terms of the frequency of ICU hospitalisation, the occurrence of organ failure (except for the occurrence of DIC syndrome), or the occurrence of complications. In the process of conducting multivariate analysis, however, we showed that, regardless of the aetiology of meningitis, the risk of the necessity for ICU hospitalisation, complications and death increased along with the age of patients.

The use of corticosteroids has been recommended in bacterial meningitis since the beginning of the $21^{\text {st }}$ century. It is proven that adjuvant corticosteroid therapy reduces the rates of hearing loss and neurological sequelae regardless of aetiology in high income countries. The use of steroids also reduces mortality rate in pneumococcal (risk ratio 0.84 with $95 \%$ confidence interval from 0.72 to 0.98 ), but not in meningococcal, meningitis or in bacterial meningitis overall [45]. In our study, all patients with meningococcal, and nearly all with pneumococcal, meningitis received corticosteroids during treatment. Therefore it is not possible to determine if their impact was significant for survival and complications.

The mortality rate for pneumococcal CSM was $21 \%$, significantly higher than that of the group infected with $N$. meningitidis, which is consistent with data from the literature (range 10-30\%) [5,35]. The mortality rate of meningococcal infections, at the level of $0 \%$, was below the range of 3-10\% found in the literature. This may result from the fact that our study did not take unconfirmed cases into account. During the collection of material the authors found isolated cases of death (shortly after admission to hospital) in which the clinical picture was very likely to indicate a meningococcal disease, although no microbiological confirmation was obtained. In addition, the result of our observations may be explained by the younger age of patients with CSM of meningococcal aetiology, a lesser internal diseases burden, and the sudden onset of the disease leading to quicker diagnosis and treatment. It should also be noted that the centre in which the patients were hospitalised is experienced in diagnosing and treating CNS infections.

\section{Conclusions}

Bacterial cerebrospinal meningitis is a life-threatening disease associated with a high risk of death as well as with serious complications. Meningococcal infections occur more frequently in young people, as opposed to pneumococcal infections, the incidence of which increases markedly with patients' age. CSM triggered by Neisseria meningitidis is characterised by the sudden and rapid development of symptoms, which allows earlier diagnosis; haemorrhagic rashes also occur more frequently and prognosis is more favourable compared to infections caused by Streptococcus pneumoniae. Regardless of the pathogen, older age and cerebrospinal fluid pleocytosis $<1,000 \mathrm{cells} / \mu \mathrm{l}$ are factors increasing the need for critical care procedures as well as the risk of death.

Given that our findings, especially time of admission and mortality rates, are in line with other studies, we conclude that the therapeutic setting of bacterial meningitis in specialistic hospitals in Poland is comparable with that of other hospitals in Western Europe.

\section{Clinical Implications/Future directions}

Since bacterial meningitis is a severe disease, establishing screening tools and risk factors for unfavourable outcomes, as well as identifying the pathogen, is crucial for management. There is a need to collect data regarding complications and patient histories after hospitalisation because there is a lack of such information in Poland.

\section{Limitations}

Our paper is characterised by several limitations. It is a single-centre retrospective analysis, which means that not all data regarding the course of the disease was available in each case. Given the 20-year timespan of data collection, the results of some laboratory tests were missing e.g. procalcitonin concentration because this parameter could not be measured until 2010, or chloride anion concentration in cerebrospinal fluid, because it was not always requested. Moreover, the number of patients in both groups was relatively low.

\section{Acknowledgments}

This research did not receive any specific grant from funding agencies in the public, commercial, or not-for-profit sectors.

\section{References}

1. Paradowska-Stankiewicz I, Piotrowska A. Meningitis and encephalitis in Poland in 2015. Przegl Epidemiol. 2017; 71(4): 493-500, indexed in Pubmed: 29415527.

2. Paradowska-Stankiewicz I, Piotrowska A. Meningitis and encephalitis in Poland in 2014. Przegl Epidemiol. 2016; 70(3): 349-357, indexed in Pubmed: 27854417.

3. Bacterial Infections of the Central Nervous System. Handbook of Clinical Neurology. 2010, doi: 10.1016/c2009-0-34222-1.

4. Department for Communicable Disease and Infection Prevention and Control. Infectious diseases and poisonings in Poland in 2016. 2017.

5. van de Beek D, de Gans J, Spanjaard L, et al. Clinical features and prognostic factors in adults with bacterial meningitis. N Engl J Med. 2004; 351(18): 1849-1859, doi: 10.1056/NEJMoa040845, indexed in Pubmed: 15509818. 
6. Adriani KS, Brouwer MC, van de Beek D, et al. Community-acquired recurrent bacterial meningitis in adults. Clin Infect Dis. 2007; 45(5): e46-e51, doi: 10.1086/520682, indexed in Pubmed: 17682979.

7. Mace SE. Acute bacterial meningitis. Emerg Med Clin North Am. 2008; 26(2): 281-317, viii, doi: 10.1016/j.emc.2008.02.002, indexed in Pubmed: 18406976.

8. Brouwer MC. Bacterial meningitis in adults: clinical characteristics, risk factors and adjunctive treatment. University of Amsterdam. 2010.

9. Berg S, Trollfors B, Claesson BA, et al. Incidence and prognosis of meningitis due to Haemophilus influenzae, Streptococcus pneumoniae and Neisseria meningitidis in Sweden. Scand J Infect Dis. 1996; 28(3): 247-252, doi: 10.3109/00365549609027166, indexed in Pubmed: 8863355.

10. Lucas MJ, Brouwer MC, van de Beek D, et al. Endocarditis in adults with bacterial meningitis. Circulation. 2013; 127(20): 2056-2062, doi: 10.1161/CIRCULATIONAHA.113.001545, indexed in Pubmed: 23596007.

11. van de Beek D, de Gans J, Spanjaard L, et al. Clinical features and prognostic factors in adults with bacterial meningitis. N Engl J Med. 2004; 351(18): 1849-1859, doi: 10.1056/NEJMoa040845, indexed in Pubmed: 15509818.

12. Bijlsma M, Brouwer M, Kasanmoentalib E, et al. Community-acquired bacterial meningitis in adults in the Netherlands, 2006-14: a prospective cohort study. The Lancet Infectious Diseases. 2016; 16(3): 339-347, doi: 10.1016/s1473-3099(15)00430-2.

13. Schut ES, Lucas MJ, Brouwer MC, et al. Cerebral infarction in adults with bacterial meningitis. Neurocrit Care. 2012; 16(3): 421-427, doi: 10.1007/s12028-011-9634-4, indexed in Pubmed: 21989842.

14. Santos LC, Simões J, Severo M, et al. Bacterial meningitis in an urban area: etiologic study and prognostic factors. Infection. 2007; 35(6): 406-413, doi: 10.1007/s15010-007-7035-6, indexed in Pubmed: 18034205.

15. Proulx N, Fréchette D, Toye B, et al. Delays in the administration of antibiotics are associated with mortality from adult acute bacterial meningitis. QJM. 2005; 98(4): 291-298, doi: 10.1093/qjmed/ hci047, indexed in Pubmed: 15760921.

16. Kepa L, Wilczek K, Karasińska M. [Meningitis and encephalitis in the years 1983-1990. Clinical observations]. Przegl Epidemiol. 1991; 45(3): 183-189, indexed in Pubmed: 1819814.

17. Wrodycki W, Kuydowicz J, Krakowiak M, et al. [Epidemiologic-clinical analysis of purulent meningitis in adults: material from the Clinic of Infectious Diseases AM in Lodz in the years 1990-1991]. Pol Tyg Lek. 1994; 49(20-22): 462-464, indexed in Pubmed: 7651915.

18. Kuchar E, Nitsch-Osuch A, Rorat M, et al. Etiology and complications of central nervous system infections in children treated in a pediatric intensive care unit in Poland. J Child Neurol. 2014; 29(4): 483-486, doi: 10.1177/0883073813477689, indexed in Pubmed: 23446804.

19. R Core Team. R: A language and environment for statistical computing 2018.

20. Lodder MC, Schildkamp RL, Bijlmer HA, et al. Prognostic indicators of the outcome of meningococcal disease: a study of 562 patients. J Med Microbiol. 1996; 45(1): 16-20, doi: 10.1099/00222615-45-116, indexed in Pubmed: 8667405.

21. Bijlsma M, Brouwer M, Kasanmoentalib E, et al. Community-acquired bacterial meningitis in adults in the Netherlands, 2006-14: a prospective cohort study. The Lancet Infectious Diseases. 2016; 16(3): 339-347, doi: 10.1016/s1473-3099(15)00430-2.

22. Stephens D, Greenwood B, Brandtzaeg P. Epidemic meningitis, meningococcaemia, and Neisseria meningitidis. The Lancet. 2007; 369(9580): 2196-2210, doi: 10.1016/s0140-6736(07)61016-2.
23. Stanek RJ, Mufson MA. A 20-year epidemiological study of pneumococcal meningitis. Clin Infect Dis. 1999; 28(6): 1265-1272, doi: 10.1086/514777, indexed in Pubmed: 10451164.

24. van Deuren M, Brandtzaeg P, van der Meer JW. Update on meningococcal disease with emphasis on pathogenesis and clinical management. Clin Microbiol Rev. 2000; 13(1): 144-66, table of contents, doi: 10.1128/cmr.13.1.144-166.2000, indexed in Pubmed: 10627495.

25. Cohn AC, MacNeil JR, Harrison LH, et al. Changes in Neisseria meningitidis disease epidemiology in the United States, 1998-2007: implications for prevention of meningococcal disease. Clin Infect Dis. 2010; 50(2): 184-191, doi: 10.1086/649209, indexed in Pubmed: 20001736.

26. Weisfelt M, van de Beek D, Spanjaard L, et al. Attenuated cerebrospinal fluid leukocyte count and sepsis in adults with pneumococcal meningitis: a prospective cohort study. BMC Infect Dis. 2006; 6: 149, doi: 10.1186/1471-2334-6-149, indexed in Pubmed: 17038166.

27. Gomez CR, Boehmer ED, Kovacs EJ. The aging innate immune system. Curr Opin Immunol. 2005; 17(5): 457-462, doi: 10.1016/j. coi.2005.07.013, indexed in Pubmed: 16084711.

28. Harboe ZB, Benfield TL, Valentiner-Branth $P$, et al. Temporal trends in invasive pneumococcal disease and pneumococcal serotypes over 7 decades. Clin Infect Dis. 2010; 50(3): 329-337, doi: 10.1086/649872, indexed in Pubmed: 20047478.

29. Thompson MJ, Ninis N, Perera R, et al. Clinical recognition of meningococcal disease in children and adolescents. Lancet. 2006; 367(9508): 397-403, doi: 10.1016/S0140-6736(06)67932-4, indexed in Pubmed: 16458763.

30. Hussein AS, Shafran SD. Acute bacterial meningitis in adults. A 12year review. Medicine (Baltimore). 2000; 79(6): 360-368, doi: 10.1097/00005792-200011000-00002, indexed in Pubmed: 11144034.

31. Pfeffer M, Braunwald E, Moyé L, et al. Effect of Captopril on Mortality and Morbidity in Patients with Left Ventricular Dysfunction after Myocardial Infarction [do weryfikacj!!!]. New England Journal of Medicine. 1992; 327(10): 669-677, doi: 10.1056/nejm199209033271001.

32. Brandtzaeg P, Dahle JS, Høiby EA. The occurrence and features of hemorrhagic skin lesions in 115 cases of systemic meningococcal disease. NIPH Ann. 1983; 6(2): 183-90, 202, indexed in Pubmed: 6676684.

33. Andreasen TJ, Green SD, Childers BJ. Massive infectious soft-tissue injury: diagnosis and management of necrotizing fasciitis and purpura fulminans. Plast Reconstr Surg. 2001; 107(4): 1025-1035, doi: 10.1097/00006534-200104010-00019, indexed in Pubmed: 11252099.

34. Alvarez EF, Olarte KE, Ramesh MS. Purpura Fulminans Secondary to Streptococcus pneumoniae Meningitis. Case Rep Infect Dis. 2012; 2012: 508503, doi: 10.1155/2012/508503, indexed in Pubmed: 22567489.

35. van de Beek D, de Gans J, Tunkel AR, et al. Community-acquired bacterial meningitis in adults. N Engl J Med. 2006; 354(1): 44-53, doi: 10.1056/NEJMra052116, indexed in Pubmed: 16394301.

36. Lagi F, Bartalesi F, Pecile P, et al. Proposal for a New Score-Based Approach To Improve Efficiency of Diagnostic Laboratory Workflow for Acute Bacterial Meningitis in Adults. J Clin Microbiol. 2016; 54(7): 1851-1854, doi: 10.1128/JCM.00149-16, indexed in Pubmed: 27170017.

37. Lynch JP. Hospital-acquired pneumonia: risk factors, microbiology, and treatment. Chest. 2001; 119(2 Suppl): 373S-384S, doi: 10.1378/ chest.119.2_suppl.373s, indexed in Pubmed: 11171773. 
38. Taylor F, Toh CH, Hoots K, et al. Towards Definition, Clinical and Laboratory Criteria, and a Scoring System for Disseminated Intravascular Coagulation. Thrombosis and Haemostasis. 2017; 86(11): 1327-1330, doi: 10.1055/s-0037-1616068.

39. Pathan N, Faust SN, Levin M. Pathophysiology of meningococcal meningitis and septicaemia. Arch Dis Child. 2003; 88(7): 601-607, doi: 10.1136/adc.88.7.601, indexed in Pubmed: 12818907.

40. Zeerleder S, Hack CE, Wuillemin WA. Disseminated intravascular coagulation in sepsis. Chest. 2005; 128(4): 2864-2875, doi: 10.1378/ chest.128.4.2864, indexed in Pubmed: 16236964.

41. Brandtzaeg P, Joø GB, Brusletto B, et al. Plasminogen activator inhibitor 1 and 2, alpha-2-antiplasmin, plasminogen, and endotoxin levels in systemic meningococcal disease. Thromb Res. 1990; 57(2): $271-$ 278, doi: 10.1016/0049-3848(90)90326-8, indexed in Pubmed: 2315889.
42. Heckenberg S. Bacterial meningitis in adults: host and pathogen factors, treatment and outcome. Universiteit van Amsterdam. 2013.

43. Østergaard C, Konradsen HB, Samuelsson S. Clinical presentation and prognostic factors of Streptococcus pneumoniae meningitis according to the focus of infection. BMC Infect Dis. 2005; 5: 93, doi: 10.1186/1471-2334-5-93, indexed in Pubmed: 16253143.

44. Weisfelt M, van de Beek D, Spanjaard L, et al. Clinical features, complications, and outcome in adults with pneumococcal meningitis: a prospective case series. Lancet Neurol. 2006; 5(2): 123129, doi: 10.1016/S1474-4422(05)70288-X, indexed in Pubmed: 16426988.

45. Brouwer MC, McIntyre P, Prasad K, et al. Corticosteroids for acute bacterial meningitis. Cochrane Database Syst Rev. 2015(9): CD004405, doi: 10.1002/14651858.CD004405.pub5, indexed in Pubmed: 26362566. 